\title{
The $75 \%$ rule: all stress incontinence procedures are alike
}

\author{
Peter L. Dwyer
}

Published online: 16 April 2011

(C) The International Urogynecological Association 2011

In the early 1980 s anterior colporrhaphy was the operation of choice for most gynecologists, with the Burch colposuspension, the long-needle suspensions of Pereyra and Stamey, and the rectus sheath fascial slings just starting to gain popularity. Howard Jones stated in the Obstetrical and Gynecology Survey that from his review of the literature all stress incontinence operations, whatever you did, had a similar success rate of around $75 \%$. This statement was probably true at that time but was a result of a lack of good comparative trials rather than a similar effectiveness of all stress incontinence procedures. This was subsequently shown to be the case when good prospective randomized studies were reported $[1,2]$. Thirty years on we are making the same mistake, using untried surgeries and assuming equivalence without evidence.

I was recently informed by the hospitals I attend that the TVT (TVT ${ }^{\circledR}$; Gynecare, Somerville, NJ) sling was to be replaced by the Gynecare TVT Exact, another retropubic sling which has a narrower, less rigid trocar and a polypropylene mesh sling which on manual traction felt less elastic. I spoke to the company representative expressing my considerable surprise, considering the extensive research history of safety and effectiveness of the TVT over the past 10 years in many different clinical situations. I had used the new TVT Exact on a number of occasions and found that the

P. L. Dwyer $(\bowtie)$

Department of Urogynecology, Mercy Hospital for Women,

University of Melbourne,

Melbourne, Australia

e-mail: pdwyer@connexus.net.au trocar was thinner and I had less feel for where the tip of the trocar needle was in the retropubic space, particularly in obese patients and where there had been previous retropubic surgery. The narrower trocar may be associated with less postoperative pain, but my company representative could not provide me with any information on this or on effectiveness and safety generally, not even retrospective studies. I said I wished to have the original TVT until they could provide me with this information.

Although I have singled out one product, this company supported the introduction of the TVT (TVT ${ }^{\circledR}$; Gynecare, Somerville, NJ) with the prospective randomized trial comparing the TVT to the Burch colposuspension by Ward and Hilton [3]. This study was strongly endorsed by Ulmsten, one of the originators of this procedure. Most of the other companies have introduced similar, but different devices with minimal or no research data published on effectiveness and safety. This was true for retropubic, transobturator or the most recent single vaginal incision mini-slings.

All surgical procedures have complications, so at best, safety is a relative concept. The retropubic slings have a higher incidence of bladder perforations and more serious albeit rare bowel or major vascular injury, while the transobturator slings are associated with more postoperative groin pain. With other complications such as voiding difficulty and overactive bladder symptoms the evidence is less clear. A number of microporous or multifilament slings have been removed from the market, mainly for an unaccepted rate of sling-related infections - these include the Protegen Sling ${ }^{\circledR}$ (Boston Scientific, Natick, MA, USA) [4], Uratape ${ }^{\circledR} /$ Obtape $^{\circledR}$ (Mentor, Santa Barbara, CA, USA) [5], Intravaginal Slingplasty ${ }^{\circledR}$ (Tyco, Mansfield, MA, USA) 
[6] and the InFast $^{\circledR}$ sling with InteMesh ${ }^{\circledR}$ (American Medical Systems, Minnetonka, MN, USA) [7]. However, many slings have already been implanted and will continue to cause infection-related complications into the future with serious consequences for many women.

So what should be done? I think there needs to be more vigilance and care on the part of national authorities in the introduction of new commercial surgical devices, which should only be used once proven effective and safe. Secondary clinicians are the gateway to these products and they need to be mindful of their responsibilities. In the past we have been too easily persuaded of the potential benefits by company representatives (medical and commercial) without waiting to see the safety and medium-term effectiveness. The single vaginal incision mini-sling has been widely introduced, with estimates of $20 \%$ market share in the USA, without any randomized prospective trials and only small single-centre trials with short-term follow-up. We should no longer assume that every operation or new device has a similar success rate and safety record, but wait until we see the evidence.

\section{References}

1. Stanton SL, Cardozo LD (1979) A comparison of vaginal and suprapubic surgery in the correction of incontinence due to urethral sphincter incompetence. Br J Urol 51(6):497-499

2. Bergman A, Ballard CA, Koonings PP (1989) Comparison of three different surgical procedures for genuine stress incontinence: prospective randomized study. Am J Obstet Gynecol 160(5 Pt 1): 1102-1106

3. Ward K, Hilton P (2002) United Kingdom and Ireland Tension-free Vaginal Tape Trial Group. Prospective multicentre randomised trial of tension-free vaginal tape and colposuspension as primary treatment for stress incontinence. BMJ 325:67-70

4. Kobashi KC, Dmochowski R, Mee SL, Mostwin J, Nitti VW, Zimmern PE, Leach GE (1999) Erosion of woven polyester pubovaginal sling. J Urol 162:2070-2072

5. Domingo S, Alama P, Ruiz N et al (2005) Diagnosis, management and prognosis of vaginal erosion after transobturator suburethral tape procedure using a nonwoven thermally bonded polypropylene mesh. J Urol 173:1627-1630

6. Baessler K, Hewson AD, Tunn R, Schuessler B, Maher CF (2005) Severe mesh complications following intravaginal slingplasty. Obstet Gynecol 106:713-716

7. Lee J, Agnew G, Dwyer PL (2011) Mesh related chronic infections in silicone coated polyester suburethral slings. Int Urogynecol J Pelvic Floor Dysfunct 22:29-35 